\title{
Robotic Systems for the Processing of Residual Soil from Construction Projects
}

\author{
K. Saito and S. Obayashi \\ Japan Industrial Robot Association
}

\begin{abstract}
In recent years there has been an increase in the amount of soil removed from construction sites. Factors contributing to this trend include a steady expansion in construction demand, larger structures, and greater use of underground spaces. In urban areas such as Greater Tokyo, processing of the residual soil from construction work has become a significant social problem and a serious impediment to the construction industry. Given the need to build more infrastructure to support what are increasingly sophisticated and diverse lifestyles, disposal of residual soil is a problem that must be solved and an issue of great concern to the people of Japan.

This document contains the results from the first year of activity by the Technical Committee on Development Strategies for Robotic Systems for the Processing of Residual Soil from Construction Projects. Committee members include many engineers who bring with them vast on-site experience in construction work.

We began by making a detailed view of how residual soil is currently processed, collating previous studies, and elucidating problem areas. From this base, we develop three new viewpoints that we use to propose feasible robotic systems able to dispose of residual soil. While there are problems to be overcome in many of the component technologies before the robotic systems proposed in this paper can be realized, the proposals are nonetheless valuable as an indication of where the construction industry will be headed in the future.
\end{abstract}

\section{INTRODUCTION}

Although some of the soil produced on construction sites is used on-site as backfill, most of it must be removed from the site and disposed of at inland receiving areas or waterfront reclamation projects, or else used as fill, landfill, or backfill material at other construction sites. Significant quantities are also being dumped into the ocean. This paper uses the generic term "residual soil" to refer to soil that is produced at and must be removed from construction sites. In recent years the quantity of residual soil has been increasing steadily, fueled by a steady increase in construction demand, larger structures, and greater use of underground spaces, a result of the increasing concentration of population in urban areas. In Greater Tokyo, for example, the amount of residual soil produced grew from 42.40 million $\mathrm{m}^{3}$ in 1975

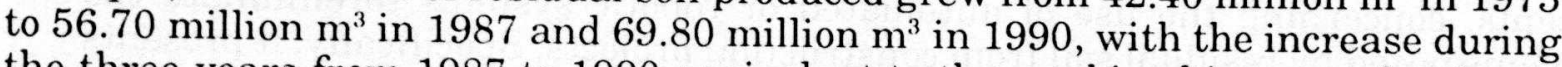
the three years from 1987 to 1990 equivalent to the combined increase for the 15 previous years. ${ }^{1}$ 
At the same time, there has emerged an absolute shortage in the number of sites available to receive the residual soil. Contributing factors include a reduction in vacant land due to continuing urbanization, land use restrictions enacted to protect the environment, and a reduction in the number of ocean reclamation projects. This is particularly true of metropolitan areas, where the shortage of receiving areas is in direct proportion to the growth in residual soil volume. The end result has been the exacerbation of a variety of problems, including longer distances to the receiving sites, higher costs for transportation and receiving, greater traffic congestion from the trucks carrying the soil, and the environmental harm caused by illegal disposal. In other words, the problem of residual soil processing is beginning to have a major impact both on construction design and work methods and on construction costs.

According to forecasts of the production and utilization of residual soil from construction projects, an estimated 847.00 million $\mathrm{m}^{3}$ of residual soil will be produced in Greater Tokyo during the 13 years from 1988 to $2000 .^{1}$ In contrast, the maximum possible utilization is estimated at 663.60 million $^{3}$, even assuming the active use of residual soil in inland housing development projects and seaside reclamation projects. This means that in the near future roughly 20 percent of all residual soil produced at construction sices in Tokyo will be left unused. The fact that construction foremen are now handling this soil on their own paints an uneasy picture for the future.

The processing of residual soil is one of the most urgent and most serious issues facing the construction industry. At the same time, we are fast approaching a time when it will nolonger be possible to process this soil using traditional methods, such as diverting it to reclamation projects or other construction sites. Thus, new ideas offering a fundamental solution to the problems associated with residual soil are called for.

\section{PURPOSE AND SCOPE OF RESEARCH}

Recently, Japan has seen wide-ranging surveys and research on the topic of residual soil from construction projects. Because the creation of measures to deal with residual soil is an important administrative issue, surveys and research are often carried out at the national or local government level for use in drafting government policy. These studies began around 1975, when the issue of residual soil processing first received attention as a problem for society.

Most of the work up to now, however, has offered analyses of existing problems or dealt with the organization and management of related information. The focus, therefore, has been on resolving current problems, and as yet there have been no concrete proposals for the future based on new concepts.

At the same time, together with the worldwide swell in concern about environmental issues, we see a questioning of traditional values about the surrounding environment and of the ideal form which construction should take. Specifically, there have been vocal calls for the elimination of the traditional priority accorded to construction productivity in favor of a new system that gives priority to production activities suited to the natural environment.

This paper offers a proposal, from a new standpoint and unbound by traditional concepts, concerning the use of automated or robotic systems to eliminate the problems posed by residual soil from construction projects. Specifically, it presents a "desirable" method for the processing of residual soil from the standpoint of the 
construction industry and based on the assumption that it will see actual use by
construction foremen.

Our basic philosoph

summarized in two points: 1) minimization of processing of residual soil can be produced; and 2) preparation of receiving sites in amount of residual soil that is residual soil that is produced. Also essentialtes in accordance with the amount of measures are environmental measures when considering residual soil counterutilization of limited resources; 2) protes such as the following: 1) the effective receiving site and prevention the natural environment 4) elimination of residual soil from construction sites.

Taking these factors into consideration, we decided to carry out surveys and analysis and submit proposals for the following:

(1) A system that minimizes residual soil production

(2) A system that utilizes residual soil as a new resource

(3) A new system for the removal and processing of residual soil

\section{PAST RESEARCH ON RESIDUAL SOIL FROM CONS'TRUCTION
PROJECTS}

When past Japanese research on residual soil is classified and collated, it can be grouped into the 12 categories listed below. $<1>$ through $<3>$ focus on systems for minimizing residual soil output, while $<4>$ through $<12>$ offer systems for the reuse of residual soil as a new resource. Figures in parentheses indicate the number of

$<1>$ Minimization of residual soil output through proper earth works planning (6)

$<2>$ Minimization of residual soil output by improving earth work methods (11)

$<3>$ Minimization of residual soil output by the on-site reuse of soil (11)

$<4>$ Development of standards for the utilization of residual soil $(>23)$

$<5>$ Collation of residual soil-related information; creation and utilization of an

$<6>$ Appropriation of residual soil over wide areas (4)

$<7>$ Transport of residual soil (9)

$<8>$ Construction of stockyards $(7)$

$<9>$ Construction of soil improvement plants (21)

$<10>$ Residual soil improvement technologies (48)

$<11>$ More construction using residual soil (16)

$<12>$ Effectiveness of using residual soil (6)

Based on these past studies, specific technical and system-related issues for the future can be divided into the two groups listed below.

A) Technical Issues

$<1>$ Technologies to improve the accuracy of residual soil-related information $<2>$ Development of methods to evaluate the effect of reusing residual soil from the standpoints of economics and the environment $<3>$ Establishment of quality standards for improved soil (based on the premise of 
active reuse) and construction management standards

$<4>$ Testing and research on the changes over time in improved soil that has been reused (surface properties, reexcavation, etc.)

$<5>$ Effect on trees of using improved soil for backfill

$<6>$ Improvements in plant equipment and operating methods for the efficient improvement of viscous soil

$<7>$ Economical methods of improving residual soil with high moisture content $<8>$ Clarification of the definitions of "soil" and "sludge" from engineering, administrative, and legal perspectives

$<9>$ Examination of construction methods for minimizing the amount of residual soil which is created or which must be removed from the site

$<10>$ Gathering of past data on the transport and utilization of residual soil

$<11>$ Development of new technologies to reduce residual soil output and allow improvements in soil quality at construction sites

$<12>$ Examination of technologies to confirm the stability of planned disposal site layouts $<13>$ Examination of methods to store, transport and check the quality of residual soil received from construction projects

$<14>$ Numerous issues remain in the area of slurry shield works:

- The development of more compact slurry treatment plants that are free from noise and vibration

- Research and development of non-polluting solidified materials for use in slurry treatment plants

- Development of more advanced detection systems for slurry and solidified materials at slurry treatment plants

- Development of more advanced system technologies for investigating subbase properties

- Development of shield technologies that eliminate the need for processing and treatment of transported soil.

<15> Planning for new soil disposal sites and development of environmental technologies

$<16>$ Establishment of earth work indicators capable of actively promoting the reuse of residual soil

B) System-related Issues

$<1>$ Establishment of a system that will improve awareness of the problem of residual soil and actively promote the utilization thereof

$<2>$ Establishment of specialized organizations for the integrated processing of related information and the coordination of supply and demand

$<3>$ Promotion of planned layouts for soil improvement facilities and stockyards and assistance measures for the construction of facilities

$<4>$ Establishment of programs to provide economic assistance, financing, and special depreciation for projects that use residual soil from construction projects $<5>$ Enhancement of systems for cooperative research in the academic and business fields $<6>$ Promotion of new projects allowing the large-scale utilization of residual soil

As can be seen from the results of past studies, a great deal of research has been conducted on systems that minimize residual soil output and systems that utilize residual soil as a new resource. As yet, however, there have been no concrete proposals concerning the transport and processing of residual soil. 


\section{A NEW PROPOSAL FOR THE PROCESSING OF RESIDUAL SOIL}

In line with the three stated objectives of this paper, we carried out diverse investigations into "desirable methods of processing residual soil" for the future. Because of the wide range of areas involved, our studies involved repeated trial and viror based on numerous assumptions to narrow the search down to several possible visions for the future. Fig. 1 shows the areas for investigation and their interrelationships. The systems proposed during the investigation process are outlined below. Needless to say, functions deemed necessary from the analysis of past studies have been included in each system. Detailed descriptions will be omitted for lack of

$<1>$ Development of a shield machine that minimizes cross-sectional area unnecessary cross section

$<2>$ Proposal of new shield machines which minimize or do not use additives $<3>$ Development of instantaneous soil drying vehicles and dump trucks equipped
with soil compacting functions

-Facilitate removal by reducing the weight and volume of residual soil $<4>$ Robotic system for the compacting of excavated soil process on residual soil

$<5>$ Robotic system for the molding of granulated soil

-Form the granulated soil on-site using excess slurry (including the hardening agent for cement) removed from subbase improvement works

$<6>$ Robot using slurry to make turf

-The inorganic sludge created during slurry shield works and other basic construction work is separated into solid and liquid components using a liquid cyclone, and the resulting substance is dewatered using electroosmosis. The dewatered sludge is then mixed with water-absorbing resins, grass seeds, and nutrients, pressurized, and sprayed over green belts. The mixture can also be compacted and formed to
create sod.

$<7>$ Robotic system for the processing of sludge

-A robotic system that performs on-site solidification of sludge (i.e., industrial waste) and uses the resulting material to form construction materials such as blocks and aggregates.

$<8>$ System for the building of man-made islands

-A soil transport robotic system designed to build man-made islands using residual soil from construction projects. Based on a self-advancing robotic transport system equipped with a global positioning system (GPS). Designed to operate only on man-
made islands. $<9>$ Mud recycling system

-An unmanned system designed to separate mud into soil and slurry on-site, transport it to a processing and treatment center, and recycle it. $<10>$ Grading and grade adjustment system

pH A robotic system that automatically grades all residual soil and adjusts grade and

$<11>$ Robotic system for the reuse and recycling of residual soil

-A robotic system for the reuse of residual soil according to the desired quality and 
Fig. 1

Areas of Investigation for a Residual Soil Processing Robotic System

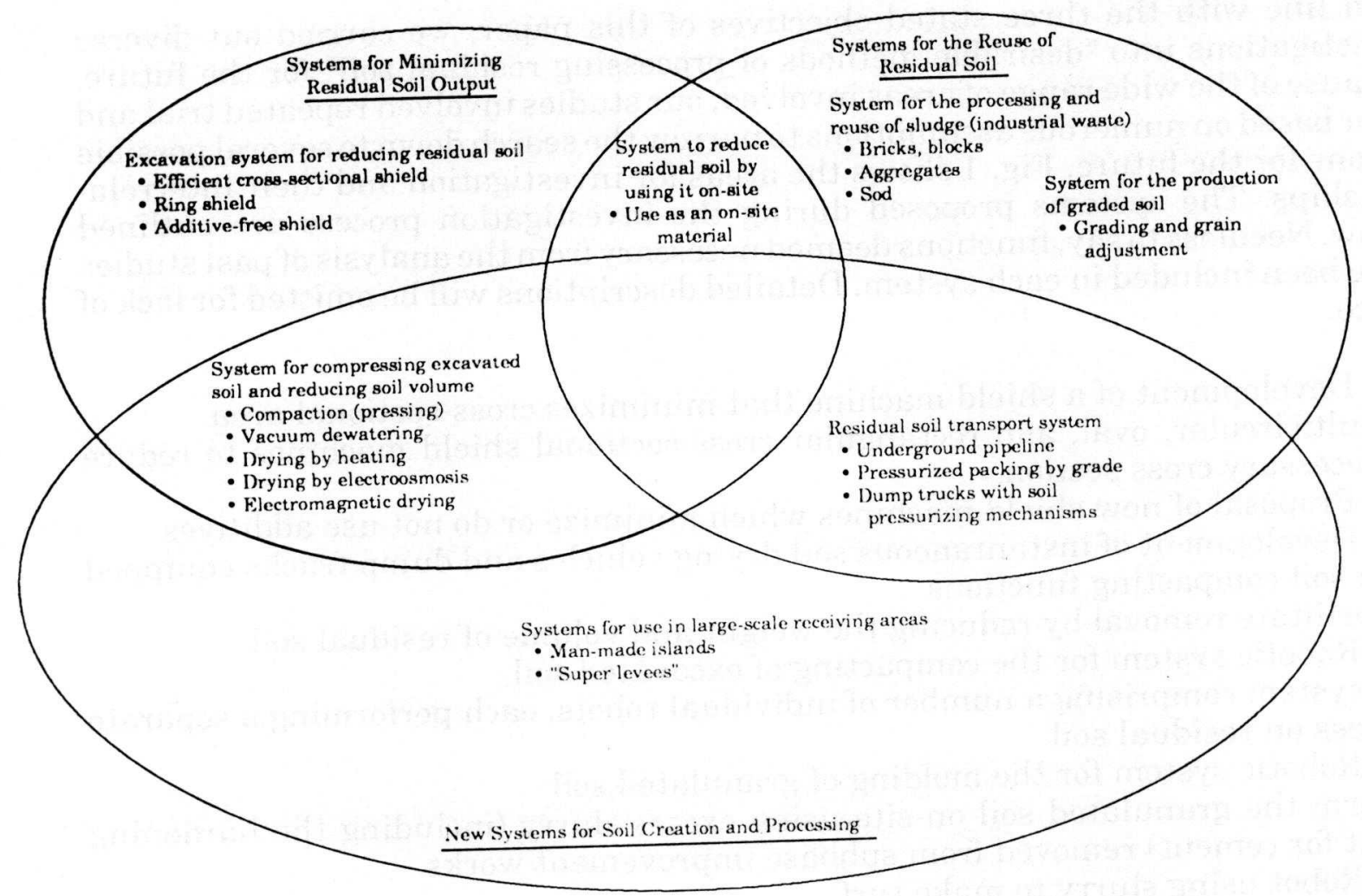

recycling as a secondary processed product

$<12>$ Robots for sea shipment and processing of residual soil

-A large-scale residual soil transport system designed for the construction of manmade islands

$<13>$ System for the separation of residual soil by soil quality and transport

-An unmanned system that automatically separates residual soil on-site according to soil quality and transports it to stockyards

The systems proposed here are robotic systems designed (or assumed) to operate with specific functions. In this paper, we would like to propose a "new comprehensive robotic system for the processing of residual soil," to be formed by integrating various systems having single functions or performing partial operations. The comprehensive robotic system is designed to build "super levees" based on adequate consideration of existing residual soil transport volumes, transport distances, and the type of use for the transported soil. In a separate sense, the super levee is an issue of major concern from the standpoint of the overcrowding of urban areas, with their extremely high concentrations of population and assets, and the prevention of 
disasters in these areas. Plans for these super levees are now being implemented in surrounding areas, and in the future such areas will be able to accept large quantities of residual soil from construction projects.

The necessary conditions, functions, and component technologies for the comprehensive soil processing system are listed below. The overall image of the comprehensive system will be omitted here from lack of space.

\section{A) Necessary Conditions}

(a) Consideration of the view from the construction site (natural view, urban view). Should not generate ill will among neighboring residents (i.e., due to dust, noise, vibration, pollution of the water supply, etc.)

(b) Safe operation and management

(c) Long-distance transport of large quantities of soil

(d) Construction of super levees

(e) Handling of all varieties of residual soil

(f) Transport speed not a primary consideration

(g) Low transport costs

B) Necessary Functions

(a) Functions for soil discrimination and screening by soil quality

-The system must have functions for discrimination of construction sludge, organic soil, fine-grained soil, sandy soil, etc. and functions for separating the soil according to the results of this discrimination.

(b) Functions for dewatering and drying of residual soil (primary processing functions)

- The system must have functions for the reduction of soil weight and volume and to facilitate handling of the soil.

(c) Functions for processing of the residual soil into products (secondary processing functions)

- The system must have functions for the processing of residual soil into bricks, aggregates, fuel, fill materials, etc. as needed.

(d) Functions for transporting the residual soil

-The system must have functions for the transport of the soil from the site where it was produced to the processing areas for discrimination and grading, and the transport of the graded soil and primary or secondary processed products to their destinations.

(e) Functions for unmanned transport and unloading

-The system must have functions for the unmanned loading, transport, and unloading of soil.

(f) Automation of earth work operations within the super levee areas

-Unmanned roller robots for packing of the soil surface

C) Necessary Component Technologies

(a) Soil discrimination techniques incorporating the latest technologies

(b) Energy-efficient dewatering and drying technologies

(c) Efficient (i.e., low-cost) product development technologies

(d) Soil improvement technologies (stable processing technologies for conversion into high-quality soil)

(e) Efficient transport technologies (land, sea, and underwater) 
(f) Technologies for unmanned transport, loading, unloading, storage, operation and management

\section{CONCLUSION}

This paper has offered a direct approach to "the processing of residual soil" from construction projects, which represents one of the most difficult problems facing the construction industry today. Following a careful analysis of numerous previous studies, we collated current technology- and system-related issues to propose a vision for the future. Although we have made some departures from current legal regulations and from engineering verification in the strict sense, we decided to give priority to the hopes and dreams of the engineers who are struggling to resolve the issues presented by the processing of residual soil. Research and development on the numerous topics branching off from our study will be continued long into the future. Nonetheless, we believe that this paper is valuable as a summary of the ideas for the near future held by young engineers working in the construction field.

The following engineers participated in the deliberations for this paper:

$\begin{array}{ll}\text { Makoto ENOMOTO } & \text { Kajima Corporation } \\ \text { Yoshinari HANYUDA } & \text { Obayashi Corporation } \\ \text { Yukichi HASHIMOTO } & \text { Maeda Corporation } \\ \text { Masaharu KATSUMATA } & \text { Maeda Corporation } \\ \text { Kazuya KIKAWADA } & \text { Hazama Corporation } \\ \text { Akira NAGATA } & \text { Kumagai Gumi Co., Ltd. } \\ \text { Hiroaki NAKAMURA } & \text { Chuo Kaihatsu Corp. } \\ \text { Yoshiyuki OHARA } & \text { Shimizu Corporation } \\ \text { Hiroshi TOIDA } & \text { Taisei Corporation }\end{array}$

\section{REFERENCES}

1 Ministry of Construction, Committee for the Study of Comprehensive Measures for Residual Soil, Report on Comprehensive Measures for Residual Soil from Construction Projects (1990). 